\title{
The Effects and Behaviours of Home Alone Situation by Latchkey Children
}

\author{
J. Rajalakshmi ${ }^{1}$, P. Thanasekaran ${ }^{2}$ \\ ${ }^{1}$ Medical-Science Department, Ambo University, Ambo, Ethiopia, East Africa \\ ${ }^{2}$ Medical-Science Department, Wollega University, Nekemte, Ethiopia, East Africa \\ Email address: \\ rajalakshmi944@yahoo.co.in (J. Rajalakshmi), thanus64@gmail.com (P. Thanasekaran)
}

\section{To cite this article:}

J. Rajalakshmi, P. Thanasekaran. The Effects and Behaviours of Home Alone Situation by Latchkey Children. American Journal of Nursing Science. Vol. 4, No. 4, 2015, pp. 207-211. doi: 10.11648/j.ajns.20150404.19

\begin{abstract}
Economic and social pressures are forcing more parents into the workplace at a time when children appear to most need adult guidance and supervision. These children, in turn, face a growing number of problems such as physical and sexual abuse, crime and delinquency, depression and suicide, drug and alcohol abuse, emotional and behavioral problems, learning difficulties, school attendance problems, domestic violence, pregnancy, abortion, and venereal disease. Many "latchkey" children experience stressful and even dangerous situations without ready access to adult guidance and support. It is estimated that as many as 10 million children care for themselves before or after school. Many latchkey kids begin their self-care responsibilities at about 8 years of age.
\end{abstract}

Keywords: Introduction, History, Statistics, Literatures, Exports Talk, Effects on Children, Parents Tips, Kids Safe

\section{Introduction}

How do parents provide supervision for their school age children when they work? School age children are sometimes left alone before and after school regularly because parents are working or otherwise not supervising. The effects of latchkey status on the normal development of children are poorly addressed in the literature. After formulating an operational definition, the prevalence, academic performance, and behavior characteristics of latchkey children were investigated in a rural area. Few differences were found to distinguish latchkey from non latchkey children. Latchkey kids are kids between the ages of 5 and 13 who take care of themselves with no adult supervision before and after school on a regular basis. The term self-care is also used to describe these children. Although children from single parent working families and lower income children do spend time home alone, children from higher incomes actually spend more hours alone. Research indicates one reason for this could be that higher income neighborhoods might feel safer to parents.

\section{History of the Terms}

The term refers to the latchkey of a door to a house. The key is often strung around the child's neck or left hidden under a mat (or some other object) at the rear door to the property. The term is claimed to have originated from an NBC documentary in 1944, due to the phenomenon of children being left home alone becoming common during and after World War II, when one parent would be enlisted into the armed forces, so the other would have to get a job. In general, the term latchkey designates "those children between the ages of five and thirteen who care for themselves after the school day until their parents or guardians return home".

\section{Statistics}

According to census data in 2011, over 4 million children were left without supervision for more than 6 hours every week on average. Because of government and grant funded afterschool programs, these numbers have dropped dramatically. In 1995 it was estimated that $18 \%$ of elementary aged children went home to empty houses. Since after-school program legislation passed in 1998, that number has dropped in all categories. The percentage of children from single parent families going home alone dropped from 24 to $14 \%$, and children of married couples with both employed dropped from over 20 to about $15 \%$. However in 
2009, budget challenges cut funding for many after school programs putting more children at risk of becoming latchkey kids.

\section{Literatures}

Much of the existing literature focuses on different between children of employed and non employed mothers by walston1973.The study which is done in Philippines on 2011 to find the relationships among four "latchkey" situation variables (length of time in self-care, hours per week in selfcare, presence of other children, and interaction with peers while in self-care), seven background/demographic variables (age, race, and sex of child; community size; family income; parents' marital status; and recent life stress), and three indices of adjustment in 97 elementary school-age latchkey children. Significant amounts of the variance in the latchkey children's anxiety, self-perceived social ability, and behavior problems were accounted for by several of the background/demographic and latchkey situation variables. The amount of variance in the 116 children's adjustment accounted for by whether or not the child was latchkey was minimal when compared to amounts accounted for by the demographic/background variables.

Woods did A pilot study investigating behavior and academic achievement for latchkey children on 1990 reported that in a sample of $108,5^{\text {th }}$ grade children of low socio-economic status, unsupervised girls exhibited market deficits in cognitive functioning as measured by intelligence test based on interview with mothers and examination of police records, finally the unsupervised children are more possibility to affect and they need mental health services.

\section{The Lonely of Latchkey Children Says Two Experts}

For more than three million American children between the ages of 6 and 13, the experience of coming home from school to Mom and apple pie is only a dream. These children end - and often even begin - their school day in houses with no adult supervision. Armed with only the key to the front door, such so-called "latchkey" kids (plus an estimated 50,000 preschoolers) fend for themselves while their parents are occupied in the workplace.

Tom Long, 43, associate professor of counselor education at Catholic University in Washington, D.C., and his wife, Lynette, 34, an assistant professor of education at Loyola College in Baltimore, know the problem well. They juggle their schedules so that one of them is home in Bethesda, Md. more than half the time with their children, Seth, 6, and Sarah, 3 . They provide room and board to a college student in exchange for watching the kids the rest of the time. Knowing that such arrangements are beyond the reach of many parents, the Longs have studied the phenomenon by interviewing not only parents, but also 300 latchkey children themselves in
Washington and its suburbs. They shared their findings with Ken Huff of PEOPLE. Lynette says that The high divorce rate has created a lot of single working parents. Right now 22 percent of all American children under 18 live with only one parent. Moreover, many married women are returning to the work force. Because of the demise of the extended family, Grandmother is less likely to watch the kids. The bulk of public funding for child care is spent for preschool children. Many people can't afford private day-care services, and even if they can, there is very little available for school-age children.

\section{Reasons for Parents Why Latchkey}

There are many reasons why some parents leave young children unsupervised, the most common of which involves employment. Single parents may have to work outside the home to support the family. Even two-parent families may need the added income earned by both working parents. In some cases, children are unsupervised because their parents are pursuing other interests or goals, such as an education. In other cases, children may find themselves in self-care because their parents are unable or unwilling to provide adequate care.

Nearly $75 \%$ of mothers whose youngest child is between ages six and 13 are in the workforce. For many single parents, especially working mothers, the absence of adult supervision may cause feelings of role confusion and guilt. Society still gives working mothers the double message that somehow they should 1) raise their children in the traditional manner of always being available at home, while 2) financially maintaining the household through employment.

Studies suggest that the parents' attitudes about the family and the workplace may significantly affect latchkey kids. When parents feel secure about their jobs and their family childcare arrangements, their children tend to feel comfortable with self-care responsibilities. When parents feel guilty about having to work or worried about the home situation, their children often reflect these anxieties in their behaviors.

\section{Effect on Children}

The effects of being a latchkey child differ with age. Loneliness, boredom and fear are most common for those younger than 10 years of age. In the early teens, there is a greater susceptibility to peer pressure, such as alcohol abuse, drug abuse, sexual promiscuity and smoking, adaptation to difficult situations, Socioeconomic status and length of time left alone can bring forth other negative effects. In one study, middle school students left home alone for more than three hours a day reported higher levels of behavioral problems, higher rates of depression and lower levels of self-esteem than other students.

Children from lower income families are associated with greater externalizing issues (such as conduct disorders and hyperactivity) and academic problems, while children from 
middle class and upper class income families are no different to their supervised peers.

\section{Key Skills to Successful Parents}

There is evidence that under the right family circumstances latchkey kids can benefit from early acceptance of self-care responsibilities, Maintain ongoing and supportive communication with the children, Be sensitive to emotional and behavioral changes in children, encourage the child to express her or his concerns, Know the attitudes and behaviors of each child's friends, Praise children honestly and openly for meeting their self-care responsibilities, Post work and emergency telephone numbers. Encourage siblings to respect and communicate with each other, Have regular family meetings. Allow each child to offer her or his input concerning all family matters. Expand the family support system to include trusted friends, relatives and neighbors who can assist in supervising or be available to children when they need help.

\section{How Parents Can Help their Latchkey Children}

For parents who must leave their children at home alone, the Longs offer these pointers:

-Teach children how to use the phone and lock the doors; list police, fire department and other important phone numbers.

-Walk through the routine with the child; some have been given keys to the house and then can't reach the lock.

-Don't let the child display a key in public - it's a sure sign he spends time alone.

-Instruct children to tell callers that the parent is "busy," rather than to indicate that they are home alone.

-Structure activities, such as an art project, a "treasure hunt" or other at-home games.

-Arrange for the child to spend some afternoons with friends to break the monotony of being alone five days a week.

-Consult with police and fire officials to burglarproof and fireproof your home as much as possible.

- Get a pet, which may help comfort the child.

- Teach children that independence and resourcefulness are virtues, but don't overload the circuits. Don't leave them alone too young or too long or give them too many responsibilities. Let them voice fears.

\section{A Phenomenon on a Rise}

According to a 2009 survey conducted by Afterschool Alliance, one out of every four children (26\%) nationwide return home after school and have no adult supervision. This 'kids in self-care' phenomenon (also known as 'latchkey kids') is a growing trend and a source of great concern.

When we think of kids staying home alone, most of us can rapidly list a number of physical safety reasons as to why this practice is worrisome and potentially perilous for our children. But, what about the psychological implications of leaving kids without supervision on a regular basis? Researchers have identified that children age 10 and younger typically express feelings of fear, loneliness, and boredom when home alone. For older children, being in self-care has been linked to behavioral problems, increased susceptibility to peer pressure, delinquency, alcohol and other drug use, smoking and teen pregnancy. We also need to consider the loss in socialization and skills building that naturally happens when children have the opportunity to interact with other children and adults.

Several states have guidelines of how old children should be before they can be home alone. Some experts recommend that no child younger than 12 should be left unsupervised. Working outside of such guidelines could be considered child endangerment or neglect by child protection agencies.

Two factors that parents cite as reasons for leaving their children home alone are financial matters and the availability of after school programs for their children. After school programs that are reputable and well-organized have shown positive social, emotional and academic benefits for children. There are many organizations around the U.S. that are taking notice and are actively trying to help working families. For instance, the Metro Atlanta YMCA has kicked off a fundraising campaign with the goal of financially aiding working families to place their children in after school programs.

So, what do we, as parents, need to consider when determining if our children should be home alone?

1. Realistically and objectively assess the physical safety and psychological effects of being home alone for each child.

2. Take into account the age and level of maturity of each child. Be mindful that even if children exhibit maturity and responsibility beyond their age, this practice may still not be in their best interest.

3. Be informed about the after school opportunities available through the school or in the community. Schools are a great resource for getting information and guidance regarding reputable after school programs and financial assistance, if needed.

4. If at all possible, opt to have the children involved in well-established after school programs.

5. Working families need the support of employers, school systems, and their community to ensure that they can provide what is best for their children. All of our children deserve a chance at a healthy start-after all, they are the future of America.

\section{Ways to Keep Your Latchkey Kid Safe after School}

Here, I've rounded up tips from Circle of Moms members who have latchkey kids as young as 9 and 10, on making sure your children stay safe while fending for themselves until 
you finish the workday.

1. Establish Ground Rules- Spell out the do's and don'ts for your child, suggest several Circle of Moms members. "Write them down, share them with your kids and post them," says Travasha F. "Make sure you include things like not going near the gas stove, or other things you don't want them near to keep them safe."

2. Discuss Safety- It may sound simple, but Circle of Moms members say it is important to sit down with your children and spell out what will keep them safe, including locking the doors, making sure they are not letting anyone in the house and how to call 911 .

3. Check-in by Phone- Many members suggest checking in by cell phone to make sure your child is safe, starting from the moment school lets out.

4. Enlist the Help of Friends and Neighbors- Reach out to friends and neighbors and ask if they would be willing to step in if your children need help.

5. Lengthen the Leash Gradually - Several members point out that both you and your child need time to get used to a daily home alone arrangement, and that you should work up to it slowly.

\section{Women, Here's How to Deal with 'Latchkey' Kids}

Mothers of kids who return from school to an empty home, deal with the biggest high-risk urban situations.It doesn't always pay to be a multi-task. Ask most women of today who on account of straddling homes and careers - have to pay collateral damage for their choice - their kids who are left home alone. These children find it toughest to be home alone, eating, studying, playing or watching time to go by waiting for parents who are out working to come home. The phenomenon terms the child as a 'latchkey' kid, who not only face loneliness, but a high risk of delinquency as well as obesity. In Mumbai itself, thousands of kids are unfortunate 'latchkey' victims. To what levels does the hazard trickle down to?PsychologistSunilTickuWali, says, "Unfortunately the effects are multi-fold. Being a parent to a latch-key kid is one of the biggest social woes that women face today. The stress levels at trying do both a job and managing a child at home, are huge. The nuclear family system is on the rise so the earlier joint family support system is lost."

\section{What Women Find Tough Coping with}

Guilt: There is the constant thought of being unable to do enough. Experts maintain that the biggest fear women have is scarring their child due to a choice they have made.

Inability to make time: With a majority part of the day outside, needless to say that mothers cannot make time to indulge a child in either homework or a hobby.

Out of control behavior: Psychologists say a parent's own reaction can go awry after a hard work day, sometimes resulting in mother's snapping at their children. Though they may not want it to be so, due to outside factors work may come home and there is a zero patience level.

No discipline: When a child does not see a parent for a large part of the day, will he or she respect them? "Often maids or ayahs who come in part-time to work, become surrogate mothers of these latchkey kids. The children know that the ultimate control is with the mother but since they depend on their maids they listen to them. Unfortunately maids also might scare a child into obeying him/her."

Poorer health levels of kids: With these kids having more reliance on pre-cooked foods, it can lead to obesity. Often, due no a lack of time, mothers don't prepare food. There is no portion control as no one is around. Parents teach these kids to pop frozen dinners into a microwave and very often leave behind money to allow their children to buy wafers and juices from a store, which is very unhealthy.

\section{Tips to Deal with the Situation}

- Making a list of what is unsafe: Write down everything that can harm a child, like a packet of cigarettes or a bottle of beer or even outdated food, and keep it out of sight.

- Have a strict talk with the child: Kids need to be told in no uncertain words about the dangers of talking with strangers or going off alone.

- Go over emergency procedures: The child must know what to do in case of a fire. Have a medical kit ready too.

\section{Summary}

Being home alone can be a frightening and potentially dangerous situation for many children and adolescents. Parents should strive to limit the times when children are home alone. Parents should prepare their children in advance for how to deal with situations that may arise. Even Many school districts has to involved in providing after-school activities and programs for latchkey kids.

\section{References}

[1] Alston, Francis Kemper. "Latch Key Children." NYU Child Study Center. $\quad$ May $1, \quad 2007$. www.aboutourkids.org/articles/latch_key_children

[2] Aragon, Debbie. "'Latch key' children as common as apple pie." Offutt Air Force Base. September 16, 2008, /www.offutt.af.mil/news/story.asp

[3] BELLE, DEBORAH. 1997. "Varieties of Self-Care: A Qualitative Look at Children's Experiences in the After School Hours." Merrill Palmer Re-search Quarterly 43:478-496.

[4] BELLE, DEBORAH. 1999. The After School Lives of Children: Alone and with Others While Parents Work. Mahwah, NJ: Erlbaum.,214-259

[5] "Communication One Key to Happy Latch key Children." Auburn University. March 4, 1992, www.ag.auburn.edu/comm/news/1992/communication. 
[6] "Do You Have a Latch key Child?" Office of Criminal Justice Planning. 2011, www.oes.ca.gov

[7] GALAMBOS, NANCY, and MAGGS, JENNIFER. 1991. "Out-of-School-Care of Young Adolescents and Self-Reported Behavior." Developmental Psychology 27:644-655.

[8] GOYETTE-EWING, MICHELE. 2000. "Children's AfterSchool Arrangements: A Study of Self-Care and Developmental Outcomes." Journal of Prevention and Intervention in the Community 20:55-67.

[9] "Latch key Children." City of Phoenix Official Website. August 20, 2003.www. phoenix.gov/FIRE/keykids.html

[10] MARSHALL, NANCY, et al. 1997. "After-School Time and
Children's Behavioral Adjustment." Merrill Palmer Research Quarterly 43:497-514.

[11] "The State of Early Childhood Programs." Center for Family Policy \& \& Research.
http://mucenter.missouri.edu/stateprograms10.pdf 2010 ,

[12] www.ncpc.org

[13] www.kidshealth.org

[14] www.safekids.org

[15] www. Education.stateuniversity.com

[16] www.popsugar.com. 